\title{
THE IMPORTANCE OF THE VALGUS HINDFOOT IN FOREFOOT SURGERY IN RHEUMATOID ARTHRITIS
}

\author{
I. STOCKLEY, R. P. BETTS, D. I. ROWLEY, C. J. M. GETTY, T. DUCKWORTH \\ From Northern General and Royal Hallamshire Hospitals, Sheffield
}

\begin{abstract}
The relationship between hindfoot deformity and forefoot pressure was assessed in 28 rheumatoid patients who had undergone forefoot reconstruction four years previously.

Patients with valgus hindfoot deformities tended to have high forefoot pressures whereas those with a normal hindfoot recorded normal pressures on the dynamic pedobarograph. All patients with residual forefoot pain recorded abnormal forefoot pressures.

We believe that orthotic control of hindfoot deformities should be considered for those patients who require forefoot surgery as a combination of surgical and orthotic management may ofier the best chance of success.
\end{abstract}

Excision arthroplasty of the metatarsophalangeal joints for the painful rheumatoid forefoot is a commonly performed procedure (Clayton 1963; Amuso et al 1971; Goldie et al 1983). The rationale is to decrease high forefoot pressures and thereby to relieve pain. Predictably, failures occur if surgery is not performed on all five metatarsophalangeal joints (Amuso et al 1971; Tillmann 1981) but poor results can also occur, without obvious cause, following an apparently comprehensive excision arthroplasty. Previously, using dynamic pedobarography, we have demonstrated that high forefoot pressures frequently occur under the first metatarsal after excision arthroplasty and have shown that this is usually associated with pain (Betts et al 1988; Stockley et al 1988). To investigate this further, the relationship between hindfoot deformity and forefoot pressures in such patients has been examined.

\section{PATIENTS AND METHODS}

We studied prospectively 35 patients with rheumatoid arthritis, whose ages ranged from $\mathbf{4 0}$ to $\mathbf{7 6}$ years (mean 57.5) who underwent forefoot arthroplasty as described

I. Stockley, MB, FRCS, Senior Orthopaedic Registrar

C. J. M. Getty, MA, FRCS, Consultant Orthopaedic Surgeon

Department of Orthopaedic Surgery, Northern General Hospital, Sheffield S5 7AU, England.

R. P. Betts, PhD, C Eng, Principal Physicist, Department of Medical Physics and Clinical Engineering

T. Duckworth, BSc, FRCS, Professor of Orthopaedic Surgery, University Department of Orthopaedic Surgery

Royal Hallamshire Hospital, Sheffield S10 2JF, England.

D. I. Rowley, MD, FRCS, Professor of Orthopaedic Surgery

University Department of Orthopaedic Surgery, Royal Infirmary, Dundee DDI 9ND, Scotland.

Correspondence should be sent to Mr I. Stockley.

(C) 1990 British Editorial Society of Bone and Joint Surgery $0301-620 X / 90 / 4124 \$ 2.00$

J Bone Joint Surg [ Br] 1990; 72-B: 705-8. by Kates, Kessel and Kay (1967). The indications for surgery and the surgical technique used have been previously reported (Stockley et al 1989).

Five patients have since died and two were unable to attend for follow-up. We have reviewed 28 patients at a mean 48.4 months (range 40 to 54 ) after operation. Bilateral procedures were performed in 19 of these and there were therefore 47 feet available for assessment. Patients were asked specifically about the presence and site of pain. Their feet were examined and foot pressure distributions were measured with a dynamic pedobarograph (Duckworth et al 1982). The degree of hindfoot valgus was measured using the tibiocalcaneal angle. This was measured, with the patient standing, by placing one arm of a goniometer in line with the calcaneus and the other in line with the tibia (Fig. 1).

Fig. 1

The tibiocalcaneal angle was measured by placing one arm of the goniometer along the tibia and the other along the midline of the calcaneum. 


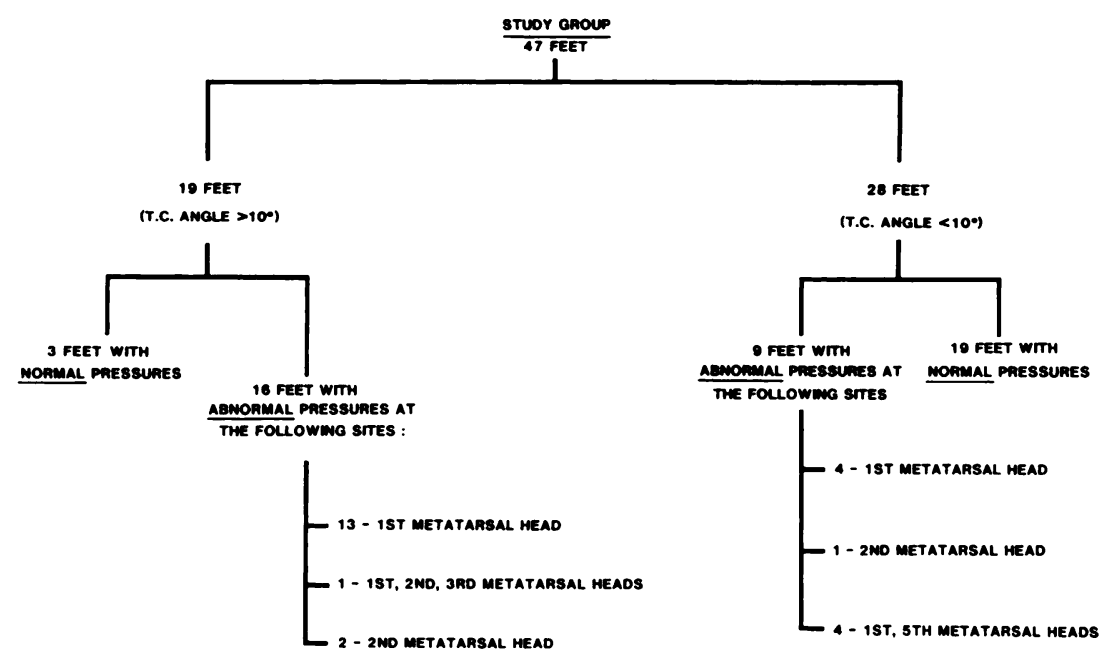

Fig. 2

Flow diagram showing the distribution of feet with measurements of the tibiocalcaneal angles and forefoot pressures.

\section{RESULTS}

Clinical assessment. Of the 28 patients, $25(89 \%)$ were satisfied with the results of their operations; two had severe pain under the first metatarsal stump which was worse than before; and one was dissatisfied with the shape of her foot. Painless walking was reported for 35 feet $(75 \%) ; 10(21 \%)$ were still painful, though less than before, and two were worse.

In seven of the 12 painful feet, the pain could be localised by the patient, six under the first metatarsal stump and one under the fifth. In the other five feet the pain was generalised.

Tibiocalcaneal angle. No patient had a varus heel; 19 feet $(40 \%)$ had valgus tibiocalcaneal angles greater than $10^{\circ}$ and $39(60 \%)$ had angles less than $10^{\circ}$.

Pedobarography. Using the Sheffield pedobarograph the maximum normal pressure under the forefoot during walking has been shown to be $10 \mathrm{~kg} / \mathrm{cm}^{2}$ (Betts, Franks and Duckworth 1980). Previously we have reported that one of the effects of forefoot arthroplasty is to shift the site of maximum load-bearing to the first metatarsal (Stockley et al 1989). In the patients described above the pressures recorded under the first metatarsals were always significantly higher than those found under the rest of the forefoot ( $p<0.0001$, Mann Whitney $U$ test). Furthermore, the pressures recorded under the first metatarsal stumps of patients with tibiocalcaneal angles greater than $10^{\circ}$ were significantly higher $(\mathrm{p}<0.0001$, Mann Whitney $U$ test) than those recorded in feet with tibiocalcaneal angles less than $10^{\circ}$.

The relationship between abnormal pressure and tibiocalcaneal angle is shown in Figure 2. Of the 19 feet with tibiocalcaneal angles greater than $10^{\circ}, 16$ had abnormal forefoot pressures whereas only nine of 28 with normal angles had abnormal forefoot pressures
( $p<0.002$, chi-square test). The majority of the abnormal pressures were confined to the medial border of the foot, and to the first metatarsal head in particular.

The 12 patients with forefoot pain all had abnormal forefoot pressures.

Clinical example. The pedobarographic results shown in Figure 3 are from a 56-year-old man with long standing rheumatoid arthritis and a tibiocalcaneal angle of $20^{\circ}$. The 10 isopressure contour plots were selected from a sequence of frames recorded from heel strike to toe off. The combined frame image, derived from superimposition of the recorded sequence, the 'areas of interest' map and the pressure/time curves for selected areas of interest show that pressure was greatest on the medial side of the foot throughout the step. During the stance phase, the pressures under the forefoot were relatively evenly distributed, but at push off the pressure is concentrated under the first metatarsal head, in this case reaching an abnormally high level.

The predominantly medial pressure bearing properties of this foot, throughout foot ground contact, are also illustrated by the plot of its centres of pressure in Figure 4. The centre of pressure is shown at $40 \mathrm{msec}$ intervals for each of 25 recorded frame images from heel strike to toe off.

\section{DISCUSSION}

The foot can be a major cause of disability in patients with rheumatoid arthritis. Often our attention is directed primarily to the forefoot. The significance of deformity and pain in the rheumatoid hindfoot is poorly documented although King, Burke and Freeman (1978) have shown that hindfoot pain was the primary cause of disability in $16 \%$ of their patients and that $42 \%$ had some 
hindfoot disability. A similar incidence of hindfoot involvement has been reported by Coughlin (1984).

Our study emphasises the importance of a valgus hindfoot, as deformities greater than $10^{\circ}$ were strongly associated with abnormally high medial forefoot pressures and poor results of forefoot surgery. Barton (1973), in his review of forefoot arthroplasty, thought that the position of the hindfoot might influence the forefoot, but no connection could be found in that series.

During normal gait, at heel strike, the leg is internally rotating, the subtalar joint abducts and the forefoot pronates. As the stance phase progresses, external rotation of the leg occurs with adduction at the subtalar joint and subsequent supination of the forefoot, ready for heel off (Inman, Ralston and Todd 1981).

In the early stages of rheumatoid arthritis, joints may become hypermobile (Dimonte and Light 1982). An increased range of movement at the talonavicular joint would allow the foot to go into excessive pronation during weight-bearing, particularly after heel strike as the leg
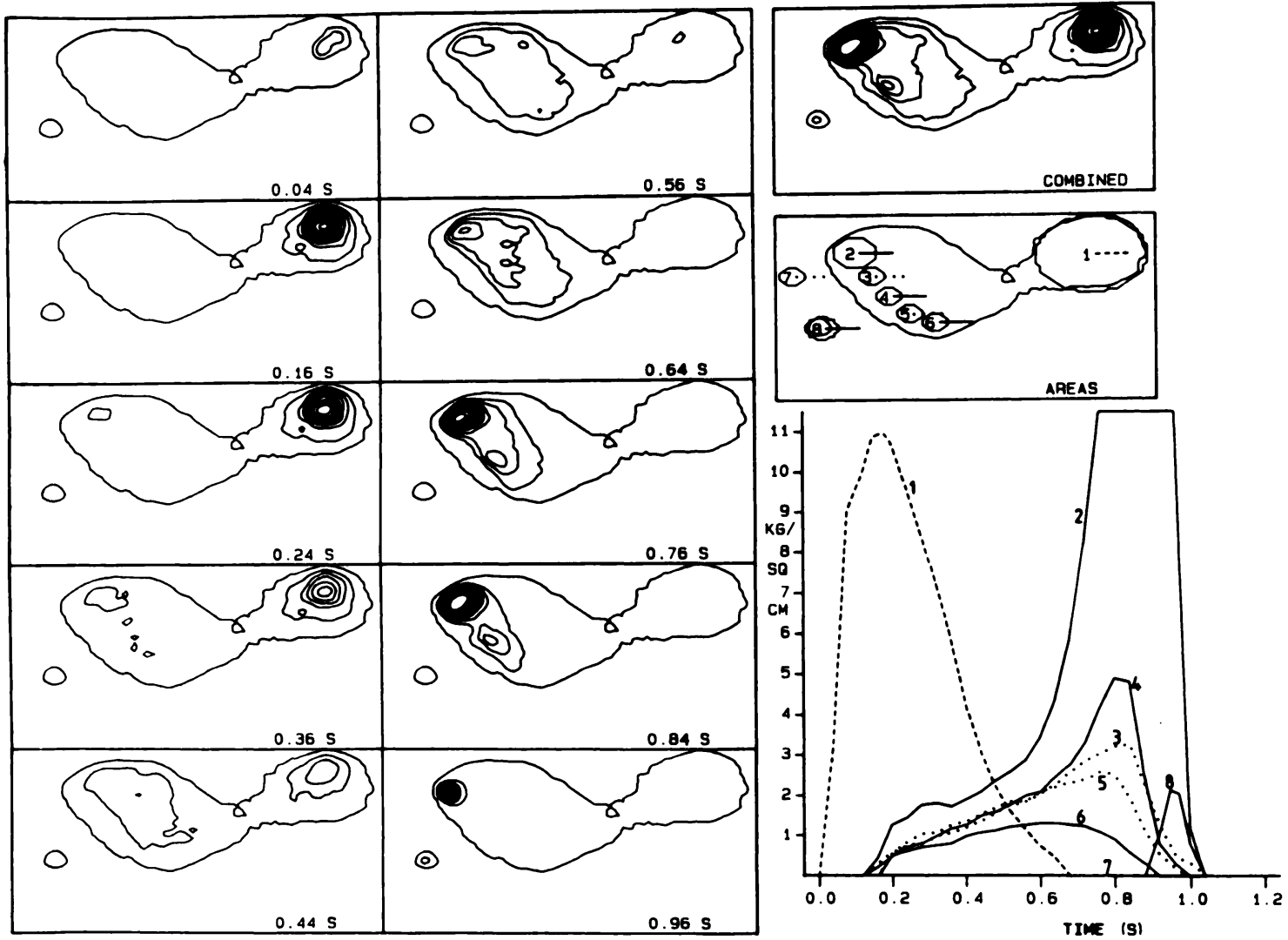

Fig. 3

Dynamic isopressure contour plots showing the variation in foot pressure throughout a footstep in a patient with a $20^{\circ}$ tibiocalcaneal angle. Note the concentration of pressures on the medial side of the heel and forefoot.

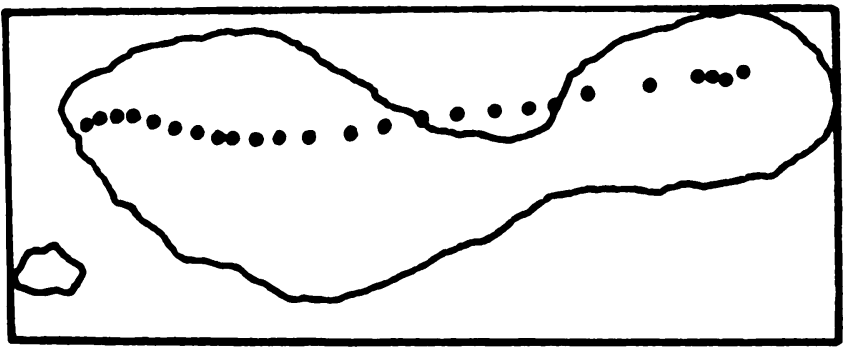

Fig. 4

Plot of the centre of pressure variation throughout the same footstep showing predominantly medial load bearing. internally rotates on the planted foot and causes subtalar eversion. The calcaneus then lies lateral to the talus while the cuboid and navicular are almost parallel. In this position, forefoot pronation also occurs at the midtarsal joints, for their normal locking mechanism is absent in such a diseased foot (Inman et al 1981).

Thus, the deformity of the subtalar and midtarsal joints so typical of progressive rheumatoid arthritis is both a direct result of the disease of those joints and an indirect result of the acquired abnormalities of the resultant gait pattern. This phenomenon may explain why forefoot surgery sometimes fails, since high medial 
forefoot pressures commonly occur in patients with valgus hindfoot deformities.

Valgus hindfoot deformity can usually be passively corrected, in the early stages of the disease, by the use of a dynamic orthosis such as a heel cup or an insole. If the deformity becomes fixed, then an orthosis cannot correct the deformity and surgery may be indicated.

As a result of our study, we believe that a combined orthotic and surgical approach may offer the best chance of success in cases of forefoot reconstruction.

No benefits in any form have been received or will be received from a commercial party related directly or indirectly to the subject of this article.

\section{REFERENCES}

Amuso SJ, Wissinger HA, Margolis HM, Eisenbeis CH Jr, Stolzer BL. Metatarsal head resection in the treatment of rheumatoid arthritis. Clin Orthop 1971; 74:94-100.

Barton NJ. Arthroplasty of the forefoot in rheumatoid arthritis. $J$ Bone Joint Surg [Br] 1973; 55-B:126-33.

Betts RP, Franks CI, Duckworth T. Analysis of pressure and loads under the foot. Part II: Quantitation of the dynamic distribution. Clin Phys Physiol Meas 1980; $1: 11$ 3-24.

Betts RP, Stockley I, Getty CJ, et al. Foot pressure studies in the assessment of forefoot arthroplasty in the rheumatoid foot. Foot Ankle 1988; 8:315-26.
Clayton ML. Surgery of the lower extremity in rheumatoid arthritis: an AAOS instructional course lecture. J Bone Joint Surg [Am] 1963; 45-A :1517-36.

Coughlin MJ. The rheumatoid foot: pathophysiology and treatment of arthritic manifestations. Postgrad Med 1984; 75:207-16.

Dimonte P. Light H. Pathomechanics, gait deviations, and treatment of the rheumatoid foot: a clinical report. Phys Ther 1982; 62 1148-56.

Duckworth T, Betts RP, Franks CI, Burke J. The measurement of pressures under the foot. Foot Ankle 1982; 3:130-41.

Goldie I, Bremell T, Althoff B, Irstam L. Metatarsal head resection in the treatment of the rheumatoid forefoot. Scand J Rheumatol 1983; 12:106-12.

Inman VT, Ralston HJ, Todd F. Human walking. Baltimore, etc: William and Wilkins, 1981.

Kates A, Kessel L, Kay A. Arthroplasty of the forefoot. $J$ Bone Joint Surg [Br] 1967; 49-B:552-7.

King J, Burke D, Freeman MAR. The incidence of pain in the rheumatoid hindfoot and the significance of calcaneo-fibular impingement. Int Orthop 1978; 2:255-7.

Stockley I, Betts RP, Getty CJM, Rowley DI, Duckworth T. Forefoot arthroplasty: a clinical and pedobarographic appraisal. $J$ Bone Joint Surg [ Br] 1988; 70-B :854.

Stockley I, Betts RP, Getty CJM, Rowley DI, Duckworth T. A prospective study of forefoot arthroplasty. Clin Orthop 1989; 248:213-218.

Tillmann K. Surgical treatment of the foot in rheumatoid arthritis. In: Goldie I, ed. Surgery in rheumatoid arthritis: an up-to-date account. 18 Reconstructive Surgery and Trauma, 1981 :195-204. 